\title{
Editorial
}

\section{Special Issue on Musical Instruments: Acoustics and Vibration}

\author{
Lamberto Tronchin $(\mathbb{D}$ \\ Department of Architecture, University of Bologna, Via dell'Università 50, 47521 Cesena, Italy; \\ lamberto.tronchin@unibo.it
}

Received: 6 May 2020; Accepted: 6 May 2020; Published: 9 May 2020

\section{Introduction}

The sound characteristics of musical instruments have been constantly growing in importance. Consequently, several congresses, workshops, and conferences have been organized in the last ten years. The studies on musical instruments, their mechanical behavior, sound emission, and characteristics started thousands of years ago, and among the physicists and mathematicians that addressed this matter, we should at least remember Leonardo da Vinci, with his experimental water organ, and Ernst Chladni, who discovered the nodal patterns on rigid surfaces, such as soundboards. The growing awareness of our intangible cultural heritage and the need to better understand our roots in the field of music have contributed to increasing the efforts to extend our knowledge in this field, defining new physical parameters, extending the analysis to other musical instruments, and developing new methods to synthesize sound from musical instruments using a simple keyboard.

These motivations led us to the proposal of a special issue called "Musical Instruments: Acoustics and Vibration" since we believe in the importance of musical acoustics within modern acoustics studies. In total, 13 papers were submitted and 8 of them were published, with an acceptance rate of $61.5 \%$. Among all the papers published, one of them was classified as a review paper, while the rest were classified as research papers. According to the number of papers submitted, and the specificity of the musical acoustics branch within acoustics, it can be affirmed that this is a trendy topic in the scientific and academic community and this special issue on "Musical Instruments: Acoustics and Vibration" aims to be a future reference for the research that is to be developed in the next few years.

\section{Musical Instruments: Acoustics and Vibration}

Human beings started to play early musical instruments in the Neanderthal age [1], a fact that helps us to understand the importance of music for the world.

The sound characteristics of musical instruments, as well as their vibrational behavior, represent one of the most important and fascinating fields of acoustics, or even of applied physics.

This aspect is sometimes neglected (or at least not investigated enough) during the restoration of ancient masterpieces, even though it is well known that their sound production is something without equal and of inestimable value.

Following this concept, this special issue aimed to contribute to the knowledge of the acoustics of musical instruments. This goal was reached by proposing (or applying) new methods for characterizing the acoustics of musical instruments, by presenting studies on some specific art pieces, or by trying to illustrate some applications in sound synthesis.

The paper by Turk et al. [1] gives an interesting review of the historical debate about the findings of the "Neanderthal musical instrument" from the "Divje Babe I Cave" (Slovenia), one of the most ancient finds related with musical instruments, at least in Europe. This paper gives a proper idea about the ancient origin of this matter. 
The two papers by Tronchin et al. [2,3] analyze completely different musical instruments. Starting from the definition of a new vibro-acoustical parameter called the intensity of acoustic radiation (IAR) [2], which was initially proposed for kettledrums, the studies were carried out to contribute to the knowledge of special and rare musical instruments. The first paper reports the results of both the modal analysis and IAR measured in a thar, a sithar, and a santoor, three important Persian musical instruments [3]. These outcomes give an idea of their behavior in response to increasing demand for knowledge of those musical instruments. The second paper describes the outcome of an experimental analysis carried out on a carabattola, a largely unknown ethnic Italian musical instrument, which used to be played in the Romagna region until the Second World War [4]. The analysis includes modal analysis and IAR measurements. It gives a unique contribution to the knowledge of this unique instrument.

The paper by Ibáñez-Arnal et al. [5] shifts the discussion to the physical properties of the material utilized for the realization of musical instruments, focusing on the carbon fiber reinforced epoxy (CFRE) prepregs, which could be used for new prototypes of new musical instruments. Undoubtedly, the physical characteristics of the materials strongly contribute to the overall assessment of the sound quality of the instruments.

The other papers focus on the application of the physics of musical instruments in the emulation of their sound production, especially during synthesis or recording. The paper by Moore [6] proposes a method for analyzing the dynamic range of sounds and music, whilst the paper by Papetti et al. [7] applies the outcomes of their previous studies into a new audio-tactile piano sample library, which is useful for real-time performances.

The last two papers analyze some specific aspects of this intriguing matter, especially from the signal processing perspective. In their paper, Jiang et al. [8] analyze the timbre perception features in musical motifs, whilst Ziemer and Plath [9] describe a method for simulating sound radiation using a microphone and loudspeaker array, going into detail about the necessary signal processing; the techniques used in both of these papers could be implemented when analyzing the non-linear components of the sound quality of musical instruments [10,11].

\section{Conclusions}

All the results presented and published in this special issue suggest that the acoustics and vibration of musical instruments is a relevant and popular topic in the scientific community. The results reported by all the authors increase the knowledge in this subject and contribute to a further understanding of this matter. This issue could become a starting point for further developments in the area of the physics of musical instruments.

Funding: This research was funded by Regione Emilia Romagna POR-FESR 2014-20 "SIPARIO" grant number PG/2018/632038.

Acknowledgments: The success of this special issue is strongly related to the huge work and the great contributions of all the authors. Furthermore, we acknowledge the hard work and the professional support of the reviewers and the editorial team of Applied Sciences. We are extremely grateful to all the reviewers involved in the issue for their time and their knowledge. We thank the assistant editors from MDPI that collaborated with us for their tireless support. We hope that the editorial process, starting from the submission and focusing on the review, was appreciated by all the authors, despite the final decisions. The real value of the time and the work spent in this process is found in the help provided to the authors to improve their papers.

Conflicts of Interest: The author declares no conflict of interest.

\section{References}

1. Turk, M.; Turk, I.; Otte, M. The Neanderthal Musical Instrument from Divje Babe I Cave (Slovenia): A Critical Review of the Discussion. Appl. Sci. 2020, 10, 1226. [CrossRef]

2. Tronchin, L. Modal analysis and intensity of acoustic radiation of the kettledrums. J. Acoust. Soc. Am. 2005, 117, 926-933. [CrossRef] [PubMed] 
3. Tronchin, L.; Manfren, M.; Vodola, V. Sound Characterization through Intensity of Acoustic Radiation Measurement: A Study of Persian Musical Instruments. Appl. Sci. 2020, 10, 633. [CrossRef]

4. Tronchin, L.; Manfren, M.; Vodola, V. The Carabattola-Vibroacoustical Analysis and Intensity of Acoustic Radiation (IAR). Appl. Sci. 2020, 10, 641. [CrossRef]

5. Ibáñez-Arnal, M.; Doménech-Ballester, L.; Sánchez-López, F. A Study of the Dynamic Response of Carbon Fiber Reinforced Epoxy (CFRE) Prepregs for Musical Instrument Manufacturing. Appl. Sci. 2019, 9, 4615.

6. Moore, A. Dynamic Range Compression and the Semantic Descriptor Aggressive. Appl. Sci. 2020, 10, 2350. [CrossRef]

7. Papetti, S.; Avanzini, F.; Fontana, F. Design and Application of the BiVib Audio-Tactile Piano Sample Library. Appl. Sci. 2019, 9, 914. [CrossRef]

8. Jiang, W.; Liu, J.; Zhang, X.; Wang, S.; Jiang, Y. Analysis and Modeling of Timbre Perception Features in Musical Sounds. Appl. Sci. 2020, 10, 789. [CrossRef]

9. Ziemer, T.; Plath, N. Microphone and Loudspeaker Array Signal Processing Steps towards a "Radiation Keyboard" for Authentic Samplers. Appl. Sci. 2020, 10, 2333. [CrossRef]

10. Tronchin, L. The Emulation of Nonlinear Time-Invariant Audio Systems with Memory by Means of Volterra Series. J. Audio Eng. Soc. 2012, 60, 984-996.

11. Tronchin, L.; Coli, V.L. Further investigations in the emulation of nonlinear systems with Volterra series. J. Audio Eng. Soc. 2015, 63, 671-683. [CrossRef]

(C) 2020 by the author. Licensee MDPI, Basel, Switzerland. This article is an open access article distributed under the terms and conditions of the Creative Commons Attribution (CC BY) license (http://creativecommons.org/licenses/by/4.0/). 